\title{
PRODUÇÃO DE SUBJETIVIDADE E DE SAÚDE NO TRABALHO DOCENTE: O GRUPO COMO ESTRATÉGIA DE REFLEXÃO DA PRÁTICA DO PROFESSOR
}

\author{
Claudia Beatriz Jotz* \\ Nedio Antonio Seminotti** \\ Rosangela Fritsch***
}

RESUMO: O objetivo geral deste estudo foi compreender, sob a ótica sistêmica complexa de Edgar Morin, como a reflexão em grupo sobre a prática docente pode se constituir em uma estratégia para a produção de subjetividade e de saúde. Realizou-se estudo de caso de um grupo operativo em uma escola estadual da cidade de Porto Alegre, no Rio Grande do Sul, tendo como referencial teórico-metodológico o paradigma sistêmico complexo. Como resultados, percebemos que a reflexão propiciou uma autoeco-organização nos sujeitos, o que gerou reflexos positivos em suas produções de subjetividade, indicando ser essa uma estratégia que produz saúde e satisfação para os professores, além de propiciar melhorias nas suas práticas diárias.

Palavras-chave: Produção de subjetividade. Complexidade. Prática docente. Grupo sistêmico complexo.

\footnotetext{
* Doutora em Psicologia pela Pontifícia Universidade Católica do Rio Grande do Sul (PUCRS). Professora da Faculdade de Negócios do Centro Universitário Ritter dos Reis (UniRitter). Pesquisadora do Grupo de Pesquisa Processos e Organizações dos Pequenos Grupos. E-mail: claudia.jotz@gmail.com

* * Doutor em Psicologia pela Universidade Autônoma de Madrid. Professor do Programa de PósGraduação em Psicologia da (PUCRS). Coordenador do Grupo de Pesquisa Processos e Organizações dos Pequenos Grupos. E-mail: nedio.seminotti@pucrs.br

* * Doutora em Educação pela Universidade do Vale do Rio dos Sinos (UNISINOS). Professora do Pograma de Pós-Graduação em Educação e do Programa de Pós-Graduação Mestrado Profissional em Gestão Educacional da Universidade do Vale do Rio dos Sinos (UNISINOS). Coordenadora do Subprojeto de Pesquisa Estudo da Evasão no Ensino Médio e Superior no Munícipio de São Leopoldo. E-mail: rosangelaf@unisinos.br
} 


\section{SUBJECTIVITY AND HEALTH PRODUCTION IN TEACHING WORK: REFLECTING ON GROUP AS A STRATEGY TO THINK OVER TEACHING PRACTICES}

ABSTRACT: The main objective of this study was to understand, under Edgar Morin's complex systemic perspective, how group reflection on teaching practices may constitute a strategy for the production of subjectivity and health. We conducted a case study of an operative group in a public state school at Porto Alegre, in the state of Rio Grande do Sul, Brazil. We elected the complex systemic paradigm as a methodological and theoretical approach. Results appointed that the act of reflecting in group granted the research participants a self-eco-organization, which affected positively on their production of subjectivity. This signalizes that this strategy might promote health and satisfaction among teachers, as well as improvements in their daily practices.

Keywords: Production of subjectivity. Complexity. Teaching practice. Complex systemic group.

\section{INTRODUC̣̃̃O}

Neste artigo, temos como tema a articulação da produção de subjetividade e de saúde com a prática docente, analisadas em pequeno grupo, sob a ótica sistêmica complexa de Edgar Morin. O pressuposto é que a inter-relação desses sistemas possibilita novos entendimentos para questões que separadamente vêm sendo pesquisadas. A Teoria da Complexidade de Edgar Morin tem sido objeto de estudo no grupo de pesquisa "Processos e Organizações nos Pequenos Grupos" - coordenado por Seminotti, vinculado à pesquisa intitulada "As Contribuições do Pensamento Complexo à Psicologia Social e aos Pequenos Grupos" - e gerado uma vasta produção acadêmica. Especialmente na elaboração deste texto, artigo de Alves e Seminotti (2006) se constituiu uma referência relevante.

A produção de subjetividade é estudada através da noção de "sujeito" de Morin (1996, 2006), que propõe uma base biológica para o entendimento desse conceito, além de dois planos antagônicos: um reflexivo, compreensivo; e outro determinista, objetivo. $\mathrm{Na}$ base biológica, temos a indicação da presença das dimensões genética e cognitiva; no plano reflexivo, vemos um sujeito que se reconhece na reflexão sobre si mesmo; e, no plano objetivo, o sujeito desaparece para dar lugar ao conhecimento científico sobre homem e sociedade. No jogo dos planos, objetivo e reflexivo, operam os conceitos de "autonomia/ dependência" e "auto-organização". O sujeito é autônomo na medida 
em que o seu meio ambiente biológico e social permite, pois necessita deste para sobreviver, tornando-se dependente; quando o sujeito faz trocas com o exterior, estas desencadeiam no sujeito um movimento de auto-organização, que é, na verdade, uma autoeco-organização, devido à inclusão de elementos do meio no sujeito.

Outro importante posicionamento teórico é a ancoragem do conceito de sujeito sobre a noção de indivíduo, que reforça a dimensão biológica desta compreensão conceitual e, por esse motivo, opõe-se aos conceitos metafísico1 e antimetafísico2 de sujeito. Nessa dimensão biológica de Morin (2006), enfatiza-se o fator computacional, ou seja, a capacidade de cada ser vivo lidar com signos, estímulos, dados e mensagens, tanto para o mundo externo como para o mundo interno. Nesse sentido, todo ser vivo é um sujeito que tem capacidade computacional para manter-se vivo, mas inclui-se aí uma grande variação de subjetividade, desde a subjetividade viva da bactéria Escherichia Coli até a subjetividade consciente humana, que opera no plano reflexivo.

Morin (2006) postula quatro princípios de identidade e um princípio de incerteza para definir a noção de sujeito. O primeiro poderia ser denominado "princípio da distinção, da diferenciação e da reunificação", pois opera a distinção entre exterior e interior, bem como permite ao sujeito uma unidade subjetiva e outra objetiva. O sujeito reflexivo se auto-observa, de forma que se percebe como um sujeito objetificado - o "eu" -, que é diferente dos outros sujeitos; ao mesmo tempo em que se percebe como sujeito observante - "Eu". Esses dois movimentos contraditórios e complementares operam a distinção entre "eu" exterior e "eu" interior e a diferenciação entre "eu" e "não eu”. Depois da distinção entre exterior e interior e da diferenciação entre "eu" e "o outro", o sujeito consegue reunificar-se em uma identidade, que comporta as duas instâncias, objetiva e subjetiva.

O segundo princípio é o da permanência da autorreferência: o "eu" se reconhece como o mesmo apesar de todas as mudanças pelas quais passam o seu corpo e os seus pensamentos. Esse é um processo recursivo, no qual o "si" remete a "si", incluindo um terceiro termo, articulando-se com a "lógica do terceiro incluído", de Nicolescu (2002), segundo a qual, no nível 1 de realidade, o "eu" na adultez não é o mesmo que o "eu" da infância, mas, no nível 2 de realidade, esses "eus" são a mesma pessoa. Abaixo, apresentamos, na Figura 1, os diferentes níveis de realidade. 
FIGURA 1: Diferentes níveis de realidade

"eu" na infância

Fonte: Elaborado pelos autores com base em Nicolescu (2002).

O terceiro e o quarto princípios estão profundamente ligados; são estes os princípios de exclusão e de inclusão. O princípio de exclusão permite que apenas o sujeito possa referir-se a si próprio, enunciando "eu", sem que isso se constitua em uma farsa; o princípio de inclusão possibilita a incorporação de características de outros ou do meio ambiente no sujeito. Este é um princípio contraditório, pois, como princípio de identidade, ele ratifica a mistura de outro no "eu". É por meio do jogo de contradição e complementaridade desses dois princípios que se forja a grande variação do sujeito, do egocentrismo extremado - a predominância da exclusão - à devoção absoluta - o predomínio da inclusão.

Dialogicamente, o indivíduo vive para si e para o outro, e essa fórmula concorrente e complementar provém de dois pontos distintos do sujeito: de seu egoísmo e de seu altruísmo. O programa altruísta destina o sujeito tanto ao "nós", representado pela família, a pátria e a espécie, como ao "ti”, representado na relação intersubjetiva de amor e amizade. Assim, a afetividade está na subjetividade, podendo propiciar tanto a abertura como a exclusão do "nós" da intersubjetividade (MORIN, 2005b).

A intersubjetividade que emerge no pequeno grupo pode ser eliciadora e estimuladora da autoprodução, dotando tal espaço da qualidade de produtor de mudanças individuais. Como o sujeito não se dilui no grupo, é permeado pela intersubjetividade em maior ou menor grau, dependendo de sua organização particular de autonomia/dependência. Conjuntamente com Luhmann (2009), afirmamos que o meio, representado pela intersubjetividade, pelas muitas vozes, as ideias e as opiniões do grupo, pode estimular a mudança, a autoeco-organização, mas não pode definir como cada sujeito irá se organizar internamente, havendo infinitas possibilidades dentro da complexidade subjetiva humana.

Recursivamente, é a comunicação o que veicula a inclusão, e esta, junto com a alteridade do sujeito, possibilita a comunicação, ou 
seja, o efeito é causador de si próprio. O sujeito, ao se sentir separado do exterior - princípio de diferenciação -, sente a necessidade de comunicar-se, e ele o faz com outro "eu", alguém que ele percebe como igual e com quem se identifica. Assim, entende-se que a qualidade do sujeito não está restrita ao egoísmo, mas ligada à comunicação e ao altruísmo (MORIN, 2006). A comunicação humana é maior que a linguagem, passando pelos processos de projeção e identificação com o outro. A linguagem está presente em todo sujeito humano, e, hoje, é impossível separar o cômputo humano da linguagem, a qual pode ser comparada a uma grande máquina auto-organizadora, que se constitui em um processo de circulação sociocultural (MORIN, 2008).

Nesse sentido, podemos dizer que todo enunciado envolve uma complexa relação entre o sujeito que comunica, a máquina linguística e o ser sociocultural, cruzando a subjetividade individual, o processo maquínico da linguagem e a autoria coletiva do discurso. É nesse ponto que emerge o princípio da incerteza, que propõe a seguinte pergunta de quem fala através do "eu": é um discurso autônomo, subjetivo, ou é um discurso coletivo? Enfim, essa é uma pergunta que permanece sem resposta, ou ainda, dialogicamente, podemos responder que são as duas coisas. Isso porque sabemos que existe uma grande variação entre sujeitos frente aos diferentes níveis de autonomia e de dependência do meio, denotando a grande complexidade da produção subjetiva em relação ao social (MORIN, 2005b, 2006, 2008).

Ao relacionar a noção de sujeito com as relações produzidas no mundo do trabalho, Fagundes, Jotz e Seminotti (2008) explicitam que a autorreferência em Morin $(1996,2006)$ é, de fato, uma autoexorreferência, assim como a auto-organização é, de fato, uma autoeco-organização, em que o sujeito, para referir-se a si mesmo, precisa referir-se ao meio ambiente. Por conseguinte, a produção de subjetividade está inter-relacionada com as relações produzidas e reproduzidas no mundo do trabalho, o que enfatiza a importância de ser analisado o contexto profissional dos docentes.

Cada vez mais, o professor tem sido cobrado na sua prática, tendo o seu papel se expandido para além da porta da sala de aula, tornando-se participante e/ou sendo responsabilizado por todo um projeto socioeducativo. A articulação entre a escola e a comunidade igualmente tem sido assumida pelos docentes, ampliando-se a demanda de trabalho sem que haja o correspondente apoio social e organizacional, potencializando-se, dessa forma, os riscos à sua saúde. Essas exigências encontram-se materializadas na Lei de 
Diretrizes e Bases da Educação Nacional (LDB), n. 9.394/96, no art. $13^{\circ}$ (BRASIL, 1996), que coloca que os docentes incumbir-se-ão de: participar da elaboração da proposta pedagógica do estabelecimento de ensino; elaborar e cumprir plano de trabalho, segundo a proposta pedagógica do estabelecimento de ensino; zelar pela aprendizagem dos alunos; estabelecer estratégias de recuperação para os alunos de menor rendimento; ministrar nos dias letivos as horas-aula estabelecidas, além de participar integralmente dos períodos dedicados ao planejamento, à avaliação e ao desenvolvimento profissional; colaborar com as atividades de articulação da escola com as famílias e a comunidade. Somando-se a isso, as avaliações em larga escala, a carência de estrutura organizacional nas escolas, a precarização das condições de trabalho têm levado muitos docentes a imprimirem um ritmo laboral excessivo, por vezes, ocupando três turnos diários com atividades, o que põe em risco a saúde destes, expondo-os a síndromes diversas que acabam por afetar a sua prática e a comunidade escolar como um todo (CODO, 1999; DIESAT, 2005; GOMES et al., 2006; ASSUNÇÃO; OLIVEIRA, 2009; CARLLOTO, 2010).

Diante dessa realidade, consideramos relevante pesquisar formas de intervenção que possam propiciar o restabelecimento da saúde desses trabalhadores da educação ou ajudar a prevenir o seu adoecimento. Em pesquisa realizada por Codo (1999) e equipe com professores de todos os Estados brasileiros, foram encontrados resultados relacionando maior suporte afetivo a menor exaustão emocional (VASQUES-MENEZES; GAZZOTTI, 1999), assim como falta de suporte social a trabalho com problemas relacionados a comprometimento e satisfação com o trabalho (SORATTO; RAMOS, 1999), o que justifica um estudo de intervenção grupal dentro do ambiente de trabalho. Em consonância com esses dados, encontramos, na literatura e nas pesquisas sobre síndrome de burnout (síndrome do esgotamento profissional), que a abordagem grupal é uma das formas de prevenção à doença (BARONA; JIMENEZ, 2005; CARLLOTO, 2010). Assim, apontamos possibilidades de enfrentamento do adoecimento docente em um plano e, em outro, aprofundamos o trabalho com grupos e o seu entendimento a partir do paradigma sistêmico complexo. Por conseguinte, entendemos que esta pesquisa se justifica no âmbito da produção de conhecimento científico dentro do paradigma sistêmico complexo e, socialmente, por lidar com um problema de saúde de grandes dimensões, estudado no mundo inteiro. 
Considerando-se o exposto, a questão que norteou o estudo foi: como a reflexão sobre a prática profissional docente no pequeno grupo, dentro do escopo sistêmico complexo, pode se constituir em uma estratégia para a produção de subjetividade e de saúde?

\section{MÉTODO}

Segundo Morin (2005a), o método é um caminho singular, percorrido em cada pesquisa, mas, para enfrentar as incertezas que se apresentam durante o trajeto, é preciso munir-se de estratégias, que são orientações éticas e metodológicas, as quais pautam o agir de cada pesquisador. A partir dessa perspectiva, realizamos uma pesquisa qualitativa, tendo como estratégia o estudo de caso, que possibilita fornecer o conhecimento aprofundado de uma realidade delimitada (YIN, 2005). Entretanto, a análise criou seu próprio caminho, propondo a integração das necessidades e dos saberes do grupo, contemplando um entendimento sistêmico do grupo de professores e gestores da escola com os alunos e a comunidade.

Esta pesquisa propôs uma intervenção sistêmica na coletividade, tendo sido organizada como um curso de extensão, com nove encontros mensais de grupo para reflexão sobre a sua prática. Ao fim do percurso, foram realizadas entrevistas individuais e seminário de avaliação com todos os sujeitos. Participaram 17 professores e gestores de uma escola da periferia de Porto Alegre, como indivíduos do grupo e, ao mesmo tempo, sujeitos que, em sua intersubjetividade, constituíram um sistema com pequeno grupo (ALVES; SEMINOTTI, 2006). Os grupos foram organizados com base na perspectiva de grupos operativos3, proposta por PichonRevière (1994), que são grupos focados no desenvolvimento de uma tarefa específica. Evidencia-se, dessa forma, que o caso estudado não se encontrou no campo de forma acabada, mas foi por meio da intervenção dos pesquisadores que se constituiu. Num primeiro momento, realizamos um caso-piloto, segundo orientação de Yin (2005), o qual propiciou que algumas técnicas de trabalho com os professores fossem revistas e que os pesquisadores pudessem se aproximar mais da cultura da escola pública estadual.

Neste estudo, articulou-se o delineamento indicado com o método em Morin (1996, 2007, 2008) dentro de uma perspectiva sistêmica complexa, com base na qual consideramos a escola como um sistema em interação com outros níveis sistêmicos e com o contexto. 
Para este percurso, utilizamos estratégias constituídas no grupo de pesquisa "Processos e Organizações nos Pequenos Grupos"4, do Programa de Pós-Graduação em Psicologia da Pontifícia Universidade Católica do Rio Grande do Sul (PUCRS), que vem trabalhando com os princípios de Morin $(2006,2007)$ na compreensão e na análise dos dados/informações obtidos na pesquisa.

Foram utilizados os seguintes operadores da complexidade: sistêmico, hologramático, auto-organização, dialógico e reintrodução do conhecedor no conhecimento. A compreensão dos dados/informações à luz destes operadores implica pressupor, respectivamente, que: a interação das partes produz novas propriedades e/ou qualidades, que são as emergências, as quais se perdem quando o sistema deixa de existir; que quase tudo do todo está nas partes e vice-versa; que todo ser vivo é autoeco-organizador e se auto-organiza em função de sua interação com o meio; que lógicas antagônicas podem ser complementares; e que toda a produção teórica é uma tradução de uma mente/ cérebro sobre a sua percepção e a sua interpretação da realidade. Foi considerado ainda o sexto operador, que é o retroativo que dá visibilidade aos efeitos de feedback, tanto negativo, que incide em sua causa, corrigindo o curso, quanto positivo, que amplia os efeitos em atuação no sistema. Já o sétimo, e último analisado, é a recursão organizacional, que postula a criação de um circuito gerador que faz com que os efeitos retornem sobre o sistema e sobre as suas causas, tornando-os causadores deles próprios. Todos esses operadores, por meio do método qualitativo, possibilitaram um novo olhar sobre a produção de subjetividade docente no pequeno grupo.

Para o tratamento das informações da pesquisa, que foram transcrições dos áudios dos encontros grupais, das entrevistas e do seminário de avaliação, foi utilizado o método de Análise Discursiva Textual (ATD), de Moraes e Galiazzi (2007), o qual inclui a perspectiva da análise de conteúdo, bem como da análise discursiva. Para os autores, esse método encontra-se no meio do caminho entre os outros dois, sendo a descrição composta das fases de unitarização e categorização, com a interpretação comportando o diálogo das categorias com a base teórica da pesquisa. Esse método foi escolhido porque, apesar de ser muito parecido com a análise de conteúdo, avança em relação à compreensão dos dados frente à complexidade, não somente expandindo o foco das partes para o todo, mas também procurando uma interpretação hermenêutica, com o seu olhar sendo produzido desde o interior do fenômeno. As categorias intermediárias 
e finais produzidas por esse método de análise/compreensão serão apresentadas na seção Discussão dos resultados.

\section{DISCUSSÃO DOS RESULTADOS}

A escola possuía, no momento da pesquisa, 17 professores, divididos por sala de aula e cargos de gestão, quatro funcionários e, aproximadamente, 240 alunos, divididos desde a primeira e até a sexta série do ensino fundamental. A decisão de participar da pesquisa foi tomada pelo grupo gestor e proposta aos professores, os quais, de uma forma geral, aceitaram, com exceção de três professoras5: "A" justificou falta de tempo, devido ao seu curso de formação; "C", impossibilidade de comparecimento aos sábados; e "I" posicionou-se contra o trabalho proposto; entretanto, todas estas participaram de pelo menos um encontro.

Inicialmente, não houve conhecimento de discordâncias internas, porém foi percebido comportamento adverso no primeiro encontro, através de "I", pois ela teve uma atitude passivo/agressiva, surpreendendo os pesquisadores. "I" foi muito importante, pois possibilitou a todos os outros professores a escolha de não participar e sair do grupo e, dialogicamente, ela valorizou o fato de estes terem aderido à proposta da pesquisa.

Ao analisarmos os dados, constatamos como é complexa a tarefa de compreendê-los, porque são multidimensionais, e, quando os olhamos mais atentamente, percebemos como é difícil não perder alguma de suas dimensões. O que as pessoas enunciam não é apenas o que está escrito na transcrição, mas também o que é transpassado pelo tom de voz, pelas expressões e pelo contexto. O tom de voz pode ser recuperado ao se ouvir a gravação, e as expressões e o contexto foram anotados no caderno de campo e na memória, mas, às vezes, fugiram ao registro.

\subsection{NATUREZA DA ATIVIDADE DOCENTE}

$\mathrm{Na}$ tentativa de minorar esses efeitos, montamos o Quadro 1 abaixo, com as categorias intermediárias e finais, construídas a partir dos relatos das reflexões pelos professores sobre a natureza da atividade profissional docente. 


\section{QUADRO 1: Categorias da natureza da atividade docente}

\begin{tabular}{|c|c|}
\hline Categorias intermediárias & Cat \\
\hline $\begin{array}{l}\text { 1. Criatividade - a profissão docente permite } \\
\text { o engajamento da criatividade pessoal nas } \\
\text { atividades do dia a dia. }\end{array}$ & $\begin{array}{l}\text { 1. Criatividade } \\
\text { o engajamen } \\
\text { atividades do }\end{array}$ \\
\hline $\begin{array}{l}\text { 2. Condução de atividades - os professores } \\
\text { refletem o quanto são acostumados a } \\
\text { conduzir as suas atividades, as pessoas e } \\
\text { as suas vidas, o quanto isso acaba fazendo } \\
\text { parte de seu jeito de ser. }\end{array}$ & \multirow{2}{*}{$\begin{array}{l}\text { 2. Efeitos da liderança - o professor, enquanto } \\
\text { líder da sala de aula, acaba assumindo a função } \\
\text { de conduzir as atividades, o que passa, muitas } \\
\text { vezes, a fazer parte de sua forma de ser e } \\
\text { também traz como efeito secundário a solidão } \\
\text { de não ter, dentro da sala de aula, alguém com } \\
\text { quem compartilhar os seus questionamentos. }\end{array}$} \\
\hline $\begin{array}{l}\text { 3. Trabalho solitário - o professor não tem } \\
\text { com quem dividir os seus pensamentos, } \\
\text { refletindo muito consigo mesmo. }\end{array}$ & \\
\hline $\begin{array}{l}\text { 4. Afetiv } \\
\text { que a } \\
\text { bom d }\end{array}$ & \multirow{5}{*}{$\begin{array}{l}\text { 3. Afetividade na atividade docente - o } \\
\text { reconhecimento da importância do uso } \\
\text { da afetividade no trabalho docente faz } \\
\text { com que os professores busquem se } \\
\text { desenvolver afetivamente para ajudar os } \\
\text { seus alunos. Ao mesmo tempo em que o } \\
\text { uso da afetividade proporciona satisfação } \\
\text { profissional quando os docentes são } \\
\text { reconhecidos e recebem o afeto de seus } \\
\text { alunos, também leva os professores a } \\
\text { trabalharem, muitas vezes, em seus limites, } \\
\text { se desgastando, se culpando por erros } \\
\text { eventuais; além disso, por vezes, eles levam } \\
\text { os problemas profissionais para casa, o que } \\
\text { aumenta o risco de desgaste emocional. }\end{array}$} \\
\hline $\begin{array}{l}\text { 5. Reconhecimento - os professores revelam } \\
\text { quanto o reconhecimento e a afetividade } \\
\text { expressos pelos alunos são gratificantes. }\end{array}$ & \\
\hline $\begin{array}{l}\text { 6. Trab } \\
\text { levad } \\
\text { limit }\end{array}$ & \\
\hline $\begin{array}{l}\text { 7. Culp } \\
\text { que } \\
\text { refle }\end{array}$ & \\
\hline $\begin{array}{l}\text { 8. Levar para casa - os docentes se percebem } \\
\text { refletindo sobre os problemas de seus } \\
\text { alunos durante o seu horário de descanso. }\end{array}$ & \\
\hline $\begin{array}{l}\text { 9. Solidariedade - o grupo reflete sobre } \\
\text { a necessidade de ser solidário, devido } \\
\text { às precárias condições de vida da } \\
\text { comunidade. }\end{array}$ & \multirow{5}{*}{$\begin{array}{l}\text { 4. Comunidade carenciada }{ }^{6} \quad-\quad \text { várias } \\
\text { dificuldades sentidas pelos professores } \\
\text { são causadas pelas peculiaridades da } \\
\text { comunidade atendida, pela sua carência } \\
\text { de recursos. Os docentes se sentem } \\
\text { instados a desenvolver a sua solidariedade, } \\
\text { questionam constantemente os seus } \\
\text { valores, devido às diferenças de visão de } \\
\text { mundo, e acabam, muitas vezes, assumindo } \\
\text { posturas assistencialistas. Em relação ao } \\
\text { convívio com a pobreza, dois sintomas são } \\
\text { observados: o primeiro é a introjeção de que } \\
\text { não são bem-sucedidos, já que seu trabalho } \\
\text { não gera recursos financeiros para aquisição } \\
\text { de bens materiais e símbolos de status, } \\
\text { tampouco o seu ambiente profissional } \\
\text { os possui. Além disso, existe um medo } \\
\text { de acabar se tornando igual às pessoas da } \\
\text { comunidade atendida, pela extinção da } \\
\text { diferença por meio da introjeção do modo } \\
\text { de serem, devido a autoeco-organização. }\end{array}$} \\
\hline $\begin{array}{l}\text { 10. Lidar com a diferença - o grupo percebe } \\
\text { como é difícil lidar com a diferença em } \\
\text { relação à visão de mundo deles próprios } \\
\text { e dos seus alunos, principalmente no que } \\
\text { tange às questões de vida e morte. }\end{array}$ & \\
\hline $\begin{array}{l}\text { 11. Assistencialismo }- \text { os professores } \\
\text { recebem treinamento do Conselho } \\
\text { Tutelar para perceber e ajudar crianças em } \\
\text { situação de risco. }\end{array}$ & \\
\hline $\begin{array}{l}\text { 12. Relevância da profissão - o convívio } \\
\text { com a pobreza e a escassez de recursos } \\
\text { na escola pública são absorvidos como } \\
\text { fracasso profissional. }\end{array}$ & \\
\hline $\begin{array}{l}\text { 13. Mimese - uma professora traz a } \\
\text { preocupação de não ficar igual à } \\
\text { comunidade onde trabalha. }\end{array}$ & \\
\hline
\end{tabular}

Fonte: Elaborado pelos autores a partir dos dados coletados. 
No primeiro encontro do grupo, a professora "C" relatou que tinha muito forte em sua personalidade a questão artística e criativa, o que poderia estar relacionado com as atividades do professor, como exercícios lúdicos, o planejamento de atividades voltadas à educação dentro da escola, como, por exemplo, o teatro elaborado para a festa de Natal. Pensando sistemicamente com Morin (2006), entendemos o sujeito como um sistema em estado estacionário de desequilíbrio ou equilíbrio dinâmico; embora pareça constante, o que efetivamente se mantém é um fluxo de energia, informação e organização que faz com que o sistema se auto-organize. Essa auto-organização é, de fato, uma autoeco-organização, pois o sujeito se organiza em consonância com o contexto ou o sistema mais amplo do qual faz parte. Assim, enquanto "C" tem uma subjetividade marcada pela condição artística e a disponibiliza em suas atividades com os alunos, ela se autoeco-organiza, incluindo, em seu sistema, a satisfação pelo seu trabalho, introduzindo, dessa forma, elementos produtores de saúde em sua autoprodução. Mesmo que Morin (2005b) não trate especificamente da atenção à saúde, ele sugere alguns caminhos na busca do bem-estar do indivíduo e da comunidade, como o exercitar da plenitude humana, de sua bipolaridade sapiens-demens6 em um circuito de relações interativas que alimentam dialogicamente a racionalidade, a afetividade, o imaginário, a mitologia, a neurose, a loucura e a criatividade humanas (MORIN, 2005b).

Como efeito da liderança em sala de aula, o professor encontra o isolamento de não ter um igual com quem compartilhar as suas dúvidas e os seus sentimentos, ao mesmo tempo em que se acostuma a tomar sozinho todas as decisões es sobre os rumos das tarefas diárias da classe. Isso apareceu no segundo encontro, na "Técnica grupal de motoristas e passageiros", em que as professoras foram estimuladas a escolher suas preferências entre ser motorista (posição mais ativa) ou passageiro (posição mais passiva). Duas professoras manifestaram gostar mais de conduzir do que de serem conduzidas; além disso, a grande maioria relatou dificuldades em deixar conduzir. Ainda, no terceiro encontro, ao refletir sobre a realidade da escola, a orientadora disse: “[...] outra pessoa já vai e pondera, e vem outra coisa, e, se tu trabalhas na sala de aula, às vezes, parece um pouco solitário nesse sentido, se tu fores pensar na questão do tempo de refletir, de amadurecer e ter uma resposta mais adequada no trabalho [...]". Percebemos que essas características podem ser causadas por um constante exercitar da liderança solitária, não desfrutando do reflexionar coletivo, do compartilhamento de acontecimentos e 
soluções. Dessa forma, cada professor vai se autoeco-organizando de forma isolada e, muitas vezes, irrefletida, encontrando no adoecimento individual o escape para as angústias geradas no seu fazer.

Devido ao caráter feminino da classe docente, muitas vezes, esta é associada aos cuidados ligados à função materna e, nesse sentido, percebida como não profissional (COSTA, 1995). Em relação a isso, tanto os docentes entrevistados por Costa (1995) como os que participaram de nossa pesquisa entendem que a afetividade contribui, em muito, para a aprendizagem dos alunos. Essa constatação vai ao encontro do que afirma Morin (2005b), sobre a afetividade invadir todas as esferas do humano, da razão à loucura, podendo abrilhantar a lógica ou prejudicá-la. A missão do ensino educativo é intersubjetiva, pois, para transmitir mais que um saber, para transmitir uma cultura e a compreensão da condição humana, é preciso que haja a circulação da afetividade, é necessário que se forme um pensar coletivo.

A afetividade, ao mesmo tempo em que possibilita, através da retroação, um feedback positivo, que retroalimenta o professor/ sistema, estimulando a sua autoeco-organização pelo sentimento de reconhecimento proveniente do meio ambiente, também torna o docente vulnerável, ao propiciar que ele seja levado aos seus limites, fazendo com que o profissional se culpe por intervenções malsucedidas e não se permita se desligar do trabalho em seus horários de descanso. A relação com a afetividade dentro da profissão é complexa, já que a afetividade, como integrante desse sujeito/sistema/professor, entra no fazer diário, impulsionando-o à auto-organização, isto é, a um questionar-se subjetivo constante. $\mathrm{E}$ esse processo, quando alijado do compartilhamento com seus colegas e exposto a grupos de alunos, pais e gestores, tende a tornarse particularmente perigoso para a saúde mental do professor.

Por outro lado, o grupo de professores da pesquisa encontram-se em uma escola que atende a uma comunidade carenciada, com dificuldades de aprendizagem que são, muitas vezes, causadas por problemas familiares e sociais. Os professores vivenciam duas realidades distintas: a realidade pessoal e a realidade profissional. Eles percebem as dificuldades dessas pessoas e reúnem esforços maiores para propiciar a aprendizagem dos alunos. Mas o que os professores, muitas vezes, não compreendem é que o sujeito carenciado (LANCETTI, 1989), vitimado, tem dificuldades para aprender, e, para que isso ocorra, é preciso mobilizar a potência deste enquanto sujeito, aumentando a sua autoestima. Isso obriga os docentes a empenharem maiores recursos psíquicos para lidar com 
esse cotidiano que lhes parece, por vezes, brutalizado. Um exemplo é quando um aluno precisa de suporte de outros profissionais porque foi espancado ou abusado. Os professores, muitas vezes sem uma rede de apoio, sentem que necessitam de auxílio e procuram o Conselho Tutelar, que os treinou para reconhecer crianças em situações de risco. Esses profissionais incorporam, assim, às suas atividades a assistência social, que, não raras vezes, se transforma em assistencialismo, por não ser sua atribuição profissional.

São muitos os profissionais que não permanecem nessa escola, mesmo com o auxílio de zona de risco, que aumenta o salário, pois não conseguem lidar com essa realidade. Se, no caso do professor que usava a sua criatividade, havia a inclusão em seu sistema de fatores positivos para a sua saúde, aqui temos a situação inversa, em que o sujeito inclui em seu sistema uma realidade difícil, que, mesmo que indiretamente, passa a ser vivenciada no cotidiano desses professores. Morin (2005a) nos ajuda a compreender essa realidade com a noção de "produção de si", como a reorganização do sujeito de forma recursiva. O sujeito se abre para a inclusão de um terceiro, que pode ser uma realidade vivenciada, e se fecha novamente, como um ser independente que incluiu algo dessa realidade em seu sistema sem deixar de ser o mesmo.

Esses professores precisam reunir forças, a fim de conseguir realizar o seu trabalho como educadores, e não podem perder o foco pedagógico; entretanto, dialogicamente, é preciso que aliem empatia, continência e suporte emocional para trabalhar com aquelas crianças. Lidar com a difícil realidade da comunidade local seria um fator para o adoecimento psicológico, não fossem a força e a coesão do grupo, que, como apoio, consegue muitas vitórias frente às dificuldades enfrentadas por todos.

Um grupo que compartilha é um grupo que transforma; quando divide os seus problemas, multiplica as suas soluções, multiplica a sua potência e a internaliza, se reconhece como grupo potente, e, hologramaticamente, cada participante reconhece-se como tal. Um exemplo dessa potência é a festa de Natal de fim de ano, organizada há cinco anos por iniciativa de uma professora, com apoio da diretora. Nessa festa, são distribuídos presentes doados pelos funcionários de um Tribunal de Justiça com sede no município: ao todo, são 240 doações, entre as quais, inúmeras bicicletas, computadores, televisões, entre outros. Não só no fim do ano a festa de Natal está presente no espírito da escola, mas também durante todo o período letivo, já que vários contratos disciplinares entre os professores e os alunos 
são feitos levando-se em consideração a expectativa do presente de natal, como também a participação em passeios organizados pela escola nesse período do ano. Muitas vezes, essas atividades podem ser classificadas como assistencialistas, por se configurarem como uma ação de ajuda pontual que não altera a realidade das crianças, entretanto, os docentes encontram satisfação ao verem que conseguiram fazer alguma diferença na vida dos seus alunos.

No que tange à relevância da profissão, o grupo se sente desvalorizado, já que o salário não é suficiente para adquirir símbolos de status e tampouco o ambiente profissional os possui. Sistemicamente, esses sujeitos sentem-se participando de uma comunidade carenciada, em uma escola sem recursos e, aos poucos, vão se auto-organizando, constituindo uma hologramaticidade, processo em que o todo do sistema se imiscui nas partes tanto quanto as partes constituem o todo. Por mais que os professores procurem aportar recursos para a comunidade, a pobreza desta vai se inscrevendo no subjetivo de cada sujeito. Uma professora, ao falar de sucesso profissional, diz o seguinte: "Eu gostaria de trabalhar num lugar que eu já trabalhei, já fui secretária, no Banco Sulbrasileiro, de diretoria, [...] num lugar que a gente podia ir mais arrumada, tu pode ter telefone, tu pode, assim, ter um computador à disposição, ter mais recursos de trabalho".

A precariedade das condições de trabalho está presente em escolas públicas estaduais, talvez em maior grau nas que se localizam nas periferias, o que acaba sendo internalizado ou significando desmerecimento dos profissionais que ali exercem as suas atividades. O grupo que não se questiona incorpora os estereótipos de sucesso da sociedade capitalista, pauta o seu sucesso pelo acesso a símbolos de status e pelo autorreconhecimento, que é a procura pelo reconhecimento de suas qualidades. Se o grupo articula um pensar coletivo, sistemicamente, ele produz emergências que o podem potencializar para um novo entendimento de seu fazer e poder, do sucesso e do fracasso. Assim, ele conseguiria apontar para uma educação planetária que rompesse com o que está posto. Nessa linha de raciocínio, concluímos que a reflexão em grupo sobre o fazer produz saúde e valorização profissional, bem como promove autoestima pessoal. Com isso, entendemos que esses processos passam necessariamente pelo intersubjetivo e o coletivo.

Outra professora expôs a sua preocupação em não ficar igual à comunidade onde trabalha, pois conhece uma colega que passou a vestir-se da mesma maneira que os alunos, parecendo moradora da vila. Existe um receio de que essa realidade seja tão significada que 
passe a ser normalizada, de que a diferença entre o meio e o sujeito professor desapareça e que este recursivamente se autoeco-organize de acordo com o ambiente. A professora falou-nos não apenas de seu receio de não conseguir produzir uma diferença para os seus alunos, de não lograr os auxiliar na construção de outra possibilidade de vida, mas também de ela sucumbir àquela realidade carenciada. Ela chamou-nos a atenção para o fato de que, no fazer diário do professor, no seu esforço para envolver os alunos com o aprendizado e, como diz Perrenoud (2000), de tecer pontes de empatia, de semelhanças, o docente não sabe nunca como vai emergir dessa mistura a que se propõe. Ele, portanto, não sabe o que deixará de seu e o que levará do outro. Mas a reflexão da professora também diz sobre um fazer solitário, sobre a falta de um grupo de pares que articule um pensamento coletivo, potencializador, o qual não se constrói em uma conversa de corredor, pois necessita de fóruns, além de espaços de fala e reconhecimento.

\subsection{A CONTRIBUIC̣ÃO DA REFLEXÃO EM GRUPO PARA A PRODUC̣̃̃O DE SUBJETIVIDADE E DE SAÚDE AOS PARTICIPANTES}

Estamos pondo em discussão o conceito de produção de subjetividade a partir de Morin (2005a), segundo o qual a informação produz neguentropia (ordem), que é um conceito contrário ao da entropia (desordem), propondo que existe uma tendência da matéria a se organizar, criar padrões de organização dentro do caos. Sendo assim, a produção de subjetividade entendida a partir do movimento neguentrópico torna cada nova informação a base para a reorganização constante, ou seja, a auto-organização do sujeito. Temos, então, que toda auto-organização é, de fato, uma autoeco-organização, já que geralmente a nova informação provém do meio, entretanto, algumas vezes, esta pode ser gerada pelo próprio sistema. A isto Morin (2005a) chama de "fatos organizadores", os quais substituem as informações provindas de fora, consideradas perturbadoras, que poderiam romper com o equilíbrio neguentrópico.

Para ser neguentrópico, é preciso ser ativamente autoprodutor de si, isto é, produzir um circuito recursivo que, constantemente, se autoproduz, se auto-organiza, mesmo que, por paradoxal que possa parecer, isso ocorra na interdependência. Seguindo essa linha de raciocínio, podemos entender a auto-organização do sujeito, realizada em função de uma nova informação, como produção de subjetividade. Esse processo é recursivo, conforme o segundo princípio de identidade, que diz que o sujeito inclui algo nele, mas sem perder a 
sua identidade; permanece o mesmo apesar das modificações que as novas informações produzem na sua subjetividade.

No grupo operativo que reflete sobre o fazer dos professores, temos uma situação privilegiada de produção de subjetividade, visto que, em conjunto, as pessoas podem ressignificar os fatos/ informações de seu dia a dia, rompendo com o isolamento da sala de aula, quando não estão com os seus pares. Nesta pesquisa, dividimos as falas produzidas nos nove encontros em avaliações que os professores fizeram do processo e em reflexões propriamente ditas. Abaixo, analisamos duas reflexões sobre a prática que geraram muito debate e, em seguida, passaremos para as avaliações.

Durante os encontros, vários foram os momentos em que o grupo conversou sobre acontecimentos marcantes de sua prática, contudo, no sexto encontro, ao discutirmos como deveria ser o perfil do professor na atualidade, duas histórias mobilizaram o grupo. "M" contou que ficou perplexa quando uma aluna, em aula, anunciou que havia acabado o seu caderno, se levantou e o jogou no lixo. A professora questionou a si própria e ao grupo sobre o valor de seu trabalho. Ela contou que, ao questionar a garota, esta respondeu que o caderno tinha terminado, não servia mais. "M"comentou com o grupo que talvez fosse ela que não estivesse acompanhando as mudanças dos tempos. Aquele era o caderno que ela havia corrigido, verificado se estava completo, se estava caprichado. A professora sentiu, então, como se seu trabalho tivesse ido parar no lixo. Essa foi uma agressão que, naquele momento, pôde ser discutida com os demais. Outra professora lembrou o momento difícil pelo qual a menina estava passando com a separação dos pais. Outras professoras falaram da mudança de valores, e algumas lembraram que ainda possuem os seus cadernos de infância. Compartilhar aquele acontecimento ajudou a professora a reencontrar o valor de seu trabalho, e, com certeza, sem os seus pares, essa informação poderia produzir uma autoorganização no sentido da desvalorização de seu trabalho. Isso nos faz pensar sobre a importância do compartilhar, desse ressignificar em grupo, que ajuda a impedir a sobrecarga emocional do professor, bem como a instalação de núcleos depressivos e/ ou de adoecimento.

Outra história foi trazida por " $T$ ", que contou que, na escola particular em que trabalha, um pai levou o seu filho para a aula na segunda-feira e pediu para que ela ficasse com o menino, porque ele não sabia o que fazer, pois a mãe do menino havia falecido no sábado anterior, vítima de aneurisma. "T" disse que só conseguia pensar que não era a pessoa mais indicada para ficar com a criança, que 
queria chorar junto com o menino, mas que todos naquela escola lhe diziam para ficar com ele na sala de aula, que era aluno dela. As outras professoras do grupo operativo ponderaram que aquele não era o momento de o menino estar na escola ou ainda que aquela era uma carga muito grande para o professor carregar. Por outro lado, pensamos que aquela situação poderia ser uma ótima oportunidade para trabalhar a condição humana, o que, segundo Morin (2003), é uma das missões da educação do futuro. A morte da mãe de um colega atualizou a possibilidade dessa perda para todos, a partir da identificação com um alter ego. Essa realidade produz angústia não apenas nos alunos como também causou na professora, a qual já havia demonstrado dificuldade em lidar com a perda. Muitas vezes, os professores são levados a enfrentar situações que superam as suas capacidades ou os limites pessoais e, se as encaram sozinhos, podem sucumbir ante aos sentimentos de fracasso e de angústia; porém, se os docentes encontram um grupo que processa o fato coletivamente, esses desafios se tornam mais leves.

"T" fez uma ponte com a história de "M", dizendo que talvez a angústia delas fosse o limite. Qual é o limite que separa o caderno do lixo ou que define quem tem que ajudar no luto do menino de 6 anos que perdeu a mãe há dois dias? Respostas para essas questões não foram dadas naquele momento, contudo, as professoras encontraram apoio, solidariedade, possibilidades de ação que fizeram a diferença entre ir para casa e continuar ruminando os problemas, o que é um sintoma do estresse profissional (AUBERT, 1993), ou compartilhar com o grupo e trabalhar a sua angústia. Podemos dizer que a chance de compartilhar e ouvir diferentes opiniões, interpretações e linhas de entendimento possibilita uma produção de subjetividade mais saudável, uma vez que o sujeito não está sozinho para lidar com as informações perturbadoras vindas do meio e a angústia que acompanha esse processo. O processamento coletivo das informações multiplica as possibilidades e as linhas de entendimento, e os sentimentos de empatia e identificação suportam as angústias, criando-se, assim, emergências que podem ter novas significações coletivas para o trabalho docente. Enquanto grupo, é mais fácil ressignificar erros do que, individualmente, criar novas formas de atuação, além de ser possível multiplicar experiências que propiciem novos estilos de aprendizagem, visto que a realidade é sempre maior e mais incerta que a nossa capacidade de prevê-la.

Os professores ponderaram que aquele momento para refletir em grupo sobre a sua prática era uma verdadeira terapia de grupo, 
que possibilitou que eles se conhecessem melhor, se enxergassem, vissem as suas carências e até definissem ações, como fazer uma excursão juntos. "L" definiu a expressão "terapia de grupo" como sair leve e estar pronta para aproveitar o sábado e o domingo; "D" sentiu que flexibilizou a forma como via as pessoas; "A" percebeu que os encontros deixaram o grupo mais coeso e disse que levou as reflexões para a sua vida.

De forma geral, as avaliações foram bastante positivas, e, em nenhum momento, alguém disse que saiu pesado ou angustiado dos encontros, embora tenham saído pensativos. Todavia, muitas pessoas disseram não gostar de trabalhar aos sábados, que foram os dias destinados aos encontros. Ao mesmo tempo em que o grupo demonstrou gostar de trabalhar coletivamente, de processar o seu fazer, ele não tem esse espaço dentro de seu tempo de trabalho. Mesmo sendo horas que precisariam ser cumpridas, elas parecem ser tiradas do horário de repouso. O trabalho docente é complexo, repleto de possibilidades e incertezas, mas está direcionado para ser realizado solitariamente ou, quando muito, com o auxílio de um(a) supervisor(a), que tem que dividir o seu tempo entre muitos docentes. Isso se reflete na aprendizagem, já que, na educação tradicional, os alunos compartilham pouco os seus sentimentos e/ou dúvidas com os professores e colegas, embora estejam juntos em sala; muitas vezes, estão individualizados frente às suas tarefas e ao professor. Ainda quanto à afetividade, Morin $(2003,2005 b)$ sugere que esta invade todas as áreas do humano, inclusive a racionalidade, podendo paralisála ou inspirá-la, e são os momentos vivenciados coletivamente que deixam as fortes lembranças, porque estão permeados pela emoção.

\section{CONSIDERAC̣ÕES FINAIS}

É importante salientar que todo conhecimento é mediado pelo conhecedor. Dessa forma, este trabalho é uma tradução dos fenômenos, mediada pelos pesquisadores, que tentaram, na medida do possível, compartilhar com os sujeitos de pesquisa esta responsabilidade no seminário de avaliação.

Com relação à natureza da atividade do professor e à produção de subjetividade, percebemos que os professores incluem em sua autoprodução vários fatores significativos de seu fazer docente, podendo estes ser eliciadores de maior ou menor saúde. Através da análise compreensiva dos relatos e das reflexões dos professores, elaboramos quatro categorias que têm como tema a natureza da 
atividade docente: criatividade, efeitos de liderança, afetividade e comunidade carenciada. Percebemos que cada uma dessas categorias aporta, para a atividade diária do docente, características que vão produzindo significações que são incorporadas em sua autoorganização, porém, observamos que existe prevalência de fatores estressantes e potencialmente causadores de doenças.

Em relação à produção de subjetividade, vimos que, quando ela provém de um trabalho de reflexão em grupo, tende a impactar positivamente a saúde do docente. Se compreendermos esse processo a partir dos princípios da complexidade de Morin (2005b, 2006), poderemos afirmar que isso ocorre porque o refletir em grupo se organiza como um pensar coletivo, que mobiliza a circulação da afetividade, o exercício da dialógica e expõe o sujeito a efeitos retroativos e recursivos que produzem um circuito gerador, propiciando a autoeco-organização, uma adaptação ativa ao meio. Os grupos de reflexão realizados com os professores foram organizados com inspiração e estruturação de grupo operativo, como proposto por Pichon-Rivière (1994), procurando-se contemplar o método sistêmico complexo, o qual já foi aplicado ao entendimento de grupos por Alves e Seminotti (2006). Inovamos ao pensar e operar a intervenção juntando transdisciplinarmente estas duas vertentes. Pichon-Rivière (1994), ao propor os grupos operativos, diz que o seu objetivo principal é a aprendizagem, e não a terapia, mas, uma vez que o método ajuda a superar o estancamento por meio da aprendizagem da realidade através da cooperação e da complementariedade na tarefa, ele permite aprender a pensar. Dessa forma, concluímos que alguns dos efeitos do grupo operativo podem ser terapêuticos, já que capacitam o sujeito a operar na realidade.

Para finalizar, é importante assinalar o inesperado, o que se apresenta sem que seja buscado. Quando propusemos a pesquisa na escola, tínhamos a intenção de trabalhar apenas com professores do ensino fundamental da quinta à oitava série, porém, quando apresentamos o projeto na reunião de professores, estes quiseram participar em conjunto, inclusive os docentes da primeira à quarta série. Dessa forma, praticamente todo o grupo de professores - incluindo, ainda, a direção - participou do curso, diferentemente do ocorrido em nossa escola-piloto, em que o estudo envolveu apenas 12 professores de um grupo de 200. Percebemos, então, que, em nosso grupo-sujeito, houve um efeito muito mais forte em termos do sistema escola, pois a intervenção influenciou a escola como um todo e, recursivamente, o grupo, gerando, consequentemente, um movimento de reflexão e autoeco-organização em nível molecular e global. 


\section{REFERÊNCIAS}

ALVES, M. C.; SEMINOTTI, N. O pequeno grupo e o paradigma da complexidade em Edgar Morin. Psicologia USP, São Paulo, v. 17, n. 2, p. 113-133, jun. 2006.

ASSUNÇÃO, A. Á.; OLIVEIRA, D. A. Intensificação do trabalho e saúde dos professores. Educação e Sociedade, v. 30, n. 107, p. 349-372, maio/ago. 2009.

AUBERT, N. A neurose profissional. In: CHANLAT, J. F. O indivíduo na organização, v. 2: dimensões esquecidas. São Paulo: Atlas, 1993.

BARONA, E. G.; JIMÉNEZ, J. C. R. Estrategias de prevención e intervención del "burnout" en el ámbito educativo. Salud Mental, v. 28, n. 5, p. 27-33, out. 2005.

BRASIL. Lei 9.394, de 20 de dezembro de 1996. "Estabelece as diretrizes e bases da educação nacional”. Diário Oficial da União, Brasília, DF, 23 dez. 1996.

CARLLOTO, M. S. Síndrome de Burnout: o estresse ocupacional do professor. Canoas: Editora ULBRA, 2010.

CODO, Wanderley. Educação, carinho e trabalho - Burnout, a síndrome da desistência do educador, que pode levar à falência da educação. Rio de Janeiro: Vozes, 1999.

COSTA, M. C. V. Trabalho docente e profissionalismo. Porto Alegre: Sulina, 1985.

DEPARTAMENTO INTERSINDICAL DE ESTUDOS E PESQUISAS DE SAÚDE E DOS AMBIENTES DE TRABALHO (DIESAT). Out. 2005. Disponível em: < http:// www.sintese-se.com.br/Boletim\%20Sa\%FAde.pdf>. Acesso em: 17 dez. 2008.

DESCARTES, R. Meditações metafísicas. 2. ed. São Paulo: Martins Fontes, [1641] 2005.

FAGUNDES, P. M.; JOTZ, C. B.; SEMINOTTI, N . Reflexões sobre os atuais modelos de gestão na produção da (inter)subjetividade dos trabalhadores. PSICO, Porto Alegre, v. 02, n. 39, p. 224-231, abr./jun. 2008.

GOMES, R. A. et al. Problemas e desafios no exercício da atividade docente: um estudo sobre o stresse, "burnout", saúde física e satisfação profissional em professores do $3^{\circ}$ ciclo e ensino secundário. Revista Portuguesa de Educação, Minho, v. 19(1), n. 1, p. 67-93, 2006.

LANCETTI, Antonio. Prevenção, preservação e progresso em saúde mental. In: LANCETTI, Antônio (org.). Saúdeloucura. v. 1. 2. ed. São Paulo: Hucitec, 1989.

LUHMANN, N. Introdução à teoria dos sistemas. Petrópolis: Vozes, 2009.

MORAES, R.; GALIAZZI, M. do C. Análise textual discursiva. Ijuí: Editora da Unijuí, 2007. MORIN, Edgar. O problema epistemológico da complexidade. Publicações EuropaAmérica, 1996.

. Os sete saberes necessários à educação do futuro. 8. ed. São Paulo: Cortez; Brasília, DF: UNESCO, 2003.

O método 1: a natureza da natureza. 2. ed. Porto Alegre: Sulina, 2005a.

. O método 5: a humanidade da humanidade, a identidade humana. 3. ed. Porto Alegre: Sulina, 2005b.

. A cabeça bem-feita: repensar a reforma, reformar o pensamento. Rio de Janeiro: Bertrand Brasil, 2006.

. Introdução ao pensamento complexo. Porto Alegre: Sulina, 2007.

O método 4: as ideias, habitat, vida, costumes, organização. 4. ed. Porto Alegre: Sulina, 2008. 
NICOLESCU, B. Fundamentos metodológicos para o estudo transcultural e transreligioso. In: ENCONTRO CATALISADOR DO PROJETO "A Evolução Transdisci-plinar na Educação". Educação e transdisciplinaridade II - CETRANS. São Paulo: TRIOM, 2002.

PERRENOUD, P. Dez novas competências para ensinar. Porto Alegre: Artes Médicas Sul, 2000. PICHON-RIVIÈRE, E. O processo grupal. São Paulo: Martins Fontes, 1994.

SEVERO, S. B.; SEMINOTTI, Nedio. O sujeito e a coletividade: um caminho transdialógico na saúde coletiva. Psicologia USP, São Paulo, v. 18, n. 4, p. 53-78, out.-dez. 2007.

SORATTO, L.; RAMOS, F. Burnout e relações sociais no trabalho. In: CODO, Wanderley. Educação, carinho e trabalho - Burnout, a síndrome da desistência do educador, que pode levar a falência da educação. Rio de Janeiro: Vozes, 1999. p. 272- 277.

VASQUES-MENEZES, I.; GAZZOTTI, A. A. Suporte afetivo e o sofrimento psíquico em Burnout. In: CODO, Wanderley. Educação, carinho e trabalho - Burnout, a síndrome da desistência do educador, que pode levar à falência da educação. Rio de Janeiro: Vozes, 1999.

YIN, R. Estudo de caso: planejamento e métodos. 3. ed. Porto Alegre: Bookman, 2005.

ZIMERMAN, D. E. Fundamentos básicos das grupoterapias. Porto Alegre: Artes Médicas Sul, 2000.

\section{NOTAS}

${ }^{1}$ A noção metafísica vem de Descartes ([1641] 2005), que concebe sujeito pelo princípio da dedução, o qual existiria antes mesmo de seu corpo e ficou conhecido como sujeito metafísico.

${ }^{2}$ A noção antimetafísica tem esta denominação por se opor à metafísica, principalmente no que se refere à imutabilidade e à interioridade do sujeito metafísico. O sujeito antimetafísico não está ligado a um indivíduo, é o conceito de sujeito pós-moderno, que concebe o sujeito como altamente mutável, com muitas identificações; várias, contraditórias entre si.

${ }^{3}$ Ressaltamos que o grupo realizado é categorizado como grupo operativo, segundo Zimerman (2000), mas o autor salienta que várias modalidades se incluem nesta categorização. Trabalhamos com grupos operativos voltados para a reflexão da sua prática profissional, neste caso, a docência, com a introdução de textos e técnicas de dinâmica de grupos, voltados para propiciar o processo reflexivo grupal.

${ }^{4}$ Inicialmente, Alves e Seminotti (2006), assim como Severo e Seminotti (2007), utilizaram para o seu estudo o método recursivo e autoeco-organizador, baseado nos princípios da complexidade de Morin (2006). Nesses dois estudos, a compreensão dos dados pesquisados foi baseada nos sete princípios para o pensamento complexo.

${ }^{5}$ Os nomes dos participantes não serão indicados para preservar-lhes a identidade; serão usadas somente as iniciais.

6 "Carenciada" foi um termo utilizado por Lancetti (1989) para destacar que a população sofre privações vitimada por um sistema capitalista, que ela não é responsável por sua carência.

${ }^{7}$ Para Morin (2005b), o homem transita entre a qualidade da racionalidade sapiens e a agressão da irracionalidade demens; ele não consegue distinguir a percepção e a alucinação, o sonho e a realidade ou o subjetivo e o objetivo, a não ser pela atividade racional do espírito, que permite essa distinção recorrendo ao meio e aos outros. 
Recebido: 13/11/2013

Aprovado: 24/11/2014

Contato:

Unisinos Programa de Pós-Graduação em Educação Av. Unisinos, 950, Cristo Rei São Leopoldo $\mid$ RS $\mid$ Brasil CEP 93.022-000 